\title{
ИСПОЛЬЗОВАНИЕ ИНТЕРАКТИВНЫХ ИГРОВЫХ ТЕХНОЛОГИЙ - КАК СПОСОБ ПОВЫШЕНИЯ МОТИВАЦИИ ОБУЧАЮЩЕГОСЯ К ЗАНЯТИЯМ
}

\author{
Кусайнова Ж. А. \\ магистр, преподаватель \\ Казахский национальный педагогический университет имени Абая, \\ Алматы, Казахстан
}

\begin{abstract}
Аннатация. В статье изучены возможности повышения знаний и склонностей, личностных качествспособностей школьника через игру. "Игра-жизненный опыт для ребенка»,-отметил М. Жумабаев, «игра-основа духовного развития ребенка», - подчеркнули в своих работах Ж. Плаже, К. Левин, Л. С. Выготский, Д. Б. Эльконин. Умение подбирать потребности в играх-зависит от мастерства учителя. Эффективнее использовать словарные игры в развитии языка школьника. Одна из таких игр - «найди нужное слово». Цель игры-учить правильно находить и произносить нужные слова, формировать внимание учащихся. Учитель называет обобщающее слово, относящееся к этому уроку, учащиеся называют или записывают нужные слова. Эта игра также учит учащихся анализировать. Место игры в педагогике, в процессе обучения известно еще со времен Платона, еще в XVIII веке Ж. Ж. Руссо и И. Г. Песталоцци объясняли, что через игру необходимо адаптировать детей к будущей жизни. Главная цель игры в процессе урока-совмещение образования с игрой. Активное участие ребенка в игре определяет и другие его действия в коллективе. Хотя игра на первый взгляд кажется простым явлением или действием, она является коллективным действием.

Abstract. The article examines the possibilities of increasing the knowledge and inclinations, personal qualitiesabilities of a student through a game. "The game is a life experience for a child," M. Zhumabayev noted, "the game is the basis of a child's spiritual development," Zh. Plage, K. Levin, L. S. Vygotsky, D. B. Elkonin. The ability to select needs in games depends on the skill of the teacher. It is more effective to use vocabulary games in the development of the student's language. One of these games is "find the right word". The goal of the game is to teach how to find and pronounce the right words correctly, to form the attention of students. The teacher calls a generalizing word related to this lesson, students name or write down the necessary words. This game also teaches students to analyze. The place of play in pedagogy, in the learning process has been known since the time of Plato, back in the XVIII century, J. J. Rousseau and I. G. Pestalozzi explained that through play it is necessary to adapt children to the future life. The main goal of the game during the lesson is to combine education with the game. The active participation of the child in the game determines his other actions in the team. Although the game at first glance seems to be a simple phenomenon or action, it is a collective action.
\end{abstract}

Ключевые слова: интерактивные методы, педагогические технологий, педагогические инноваций, активизация познавательной деятельности, виды игр, интерактивные игры.

Keywords: interactive methods, educational technology, pedagogical innovation, activation of cognitive activity, types of games, interactive games.

Президент Республики Казахстан Н.А. Назарбаев сообщил народу Казахстана в 2012 году в своем послании по названию

« Социально-экономическая модернизация - главное направление развития Казахстана», и не зря в этом послании было сказано о внедрении современных способов и технологии в систему образования. По интересам нынешнего времени, для того, чтобы завлечь учеников к образованию, учителям были поставлены новые требования. Каждая технология отличается новыми способами. Выгодно использовать разные способы развивает мышление детей. При помощи новых способов можно разузнать: что знал, что узнал и чему научился ученик.

Как говорится «Благое дело - хорошее начало», в нынешнее время предпочтения образования в направлении формирования будущего гражданина - главная политика нашей страны. Для выгодного влияния развития знания и науки нужно: внедриться во всемирное пространство знании, демократизировать обучение, определить систему обязанности и образования. По спросам нынешнего времени, предоставила способам обучения новые требования. Наша цель - формирование личности, которая поможет развитию личного и общественного интереса по приспособлению к развивающейся изменчивой среде. В какой бы среде не находился ученик, он должен уметь организовывать и совладать своими действиями. Для того, чтобы ученик достиг такого уровня, нужно акцентировать внимание на видах способа обучения, и повысить качество знания.

В Послании народу Казахстана Президент Нурсултан Назарбаев сказал: «Конкурентоспособность страны определяется в первую очередь уровнем ее образования. Полноценное вхождение в мировое образовательное пространство, несомненно, потребует поднятия системы образования на международный уровень. В любом возрасте воспитательный процесс осуществляется прежде всего через деятельность, действия и занятия воспитателя. 
Помимо быстро развивающихся технологий, повышающих активность процесса обучения, существует интерактивная игровая технология, предполагающая моделирование игры на основе учебного опыта. Его преимущества многогранны, он эффектен и востребован.

Возможности интерактивной игровой технологии очень широки.

- позволяют сочетать глубину проблемы и многообразие их смысла;

- Готовит к структурированному профессиональному общению, добавляет моменты социального взаимодействия, соответствует логике действий;

- стимулирует их непроизвольную активность, позволяет вовлечь участников в процесс обучения;

- насыщен обратной связью («здесь и сейчас»), более содержательной и комплексной, чем применяемые методы повышения активности образовательного процесса;

- корректирует самооценку, легко избавляется от стереотипов, формирует ценности взглядов и профессиональных действий;

- понимает полученные результаты, предлагает возможность всестороннего анализа и интерпретации, стимулирует развитие рефлекторных процессов у учащихся;

- позволяет проявить все качества личности, ее положительные и отрицательные черты личности, стиль делового партнерства; [2, стр. 108].

Кроме того, назначение игровых технологий зависит в основном от практических потребностей учащихся.

Интерактивные игры используются как решение различных задач: обучение, принятие хозяйственных решений, организованная проектная работа, исследования, разработки.

Существуют некоторые отличия в обучении интерактивной игровой технологии:

$\checkmark$ Игровое обучение имитирует любой аспект человеческой деятельности;

$\checkmark$ У участников игрового тренинга разнообразные игровые или профессиональные роли, они стимулируются и вызывают интерес;

$\checkmark$ Игровая деятельность регулируется системой правил, штрафов и поощрений;

$\checkmark$ Пространственно-временные характеристики модели действия вносят кардинальные изменения в обучение игре;

$\checkmark$ Большинство деловых и симуляторных игр носит условный характер;

$\checkmark$ Форма регламентации процесса игрового взаимодействия состоит из следующих групп: концептуальная, визуальная, постановочная, этапная, экспертный пакет, тестирование и рефлексия, группа информационного сопровождения и группа оценки участников игры.

Что касается видов интерактивной игровой техники:

Виды интерактивной игровой техники:

$\checkmark$ Обучение;

$\checkmark$ Нейролингвистический тренинг (НЛТ);

$\checkmark$ Экстремальные тренировки на природе;

$\checkmark$ Тимбилдинг;

$\checkmark$ Видео обучение;

Обучение: Игра - одна из самых популярных интерактивных технологий на сегодняшний день. Основой здесь является профессиональное сотрудничество. Его основная цель - формирование человека как личности в процессе профессиональной деятельности через развитие психодинамических качеств, персонализацию его эмоций, интеллекта, метакомпетентности. На тренинге решаются следующие задачи:

- Практическое применение знаний, науки и навыков в профессиональном взаимодействии;

- Демонстрировать, раскрывать, понимать личный стиль, манеру общения и т.д. [3, стр. 112].

Нейролингвистический тренинг: тип процессного обучения, основанный на использовании эксклюзивной технологии NLB. Его авторы - Джон Гриндер (лингвист) и Ричард Бэндлер (математик и программист). NLB (нейролингвистическое программирование) основано на изучении мышления, языка и поведения. Он предполагает, что в любом бизнесе или поведении есть три различных элемента. Прежде всего, это внутреннее поведение, потому что человек говорит то, что он делает руками. Во-вторых, у человека есть внутренний счет, потому что человек делает то, что думает, одинаково. В-третьих, человек соревнуется изнутри, потому что он это чувствует. Анализируя эти три процесса, можно создать абсолютно полную модель любого образцового поведения. Эту модель может использовать любой компетентный человек, просто изменив процесс, изменив звуковую волну, создав точное изображение и получив впечатление.

Экстремальные тренировки на природе - позволяет экспериментировать и участвовать в различных экспериментах. Контраст между дикой природой и обычным рабочим местом многому учит. Однако неопытный преподаватель может и не воспользоваться возможностями экстремального обучения. Выезды на природу, изготовление необходимых вещей из веревок и досок, прогулки по веревочным мостам, восхождение на 
вершины гор, ориентирование на местности приучает учащихся к совместной работе, формирует групповую работу.

Физическое и эмоциональное взаимодействие с живой природой, ее красота и безмятежность, а также суровые условия - укрепляет чувства и регулирует их поведение, действия, мотивацию, отношения с окружающими. Специалисты считают, что непредсказуемые воздействия природы иногда сказываются на восприятии людьми быстро меняющегося мира.

Тимбилдинг - в последнее время групповые тренировки стали более популярными. Обучает коммуникативной компетенции на первом этапе развития участников группы. Учит устанавливать дружеские отношения в группе, регулировать сотрудничество, определять этические нормы и принципы совместных действий, создавать атмосферу равноправия и доброжелательности, поддерживать. На втором этапе развития группы выделяются союзы и подгруппы внутри группы, когда возникает конфликт за «справедливость» в распределении ролей и ролей на враждебной стадии. Он объединяет людей из одной группы. Именно здесь начинается развитие интерактивной компетенции. В зависимости от способности лидера группы создать команду во время обучения, это придаст силы другим членам команды для положительного решения проблемы и установления общих ценностей. [5, стр. 123].

Очевидно, что слово «видеотренинг» основано на использовании видео во время обучения. Различают два основных способа использования видео для целей чтения: показ предварительно записанного видео (просмотр видео), использование записи при выполнении игровых заданий, ее просмотр и анализ (обратная связь).

Целью видеотренинга является развитие навыков структурного поведения и общения, создание необходимой психологической обстановки. Просмотр готового видео позволяет выполнять следующие задачи: информатизация, решение задач, развитие знаний и навыков. Информационное видеонаблюдение используется как средство передачи больших объемов информации. Например: о качестве и характере новой обучающей услуги, об истории организации и т. д. Просмотр видео для развития знаний и навыков - это еще и комплексная модель решения задач, обсуждение структурных и эффективных действий, демонстрация паттернов и поведенческих подходов.

Видеообучение представляет собой интерактивный игровой урок. Студенты разыгрывают небольшие ситуации, возникающие в результате деловых или межличностных взаимодействий. Все это записывается на видеокамеру, затем записанный материал просматривается под руководством преподавателя - осуществляется обратная связь. Спектакль состоит из обсуждения и анализа, а также вербальных и невербальных продуктов участников. Обратная связь помогает участникам научиться понимать и размышлять над опытом. Это позволяет вам напрямую использовать свой личный опыт и использовать его как дифференцированный, повторно просмотренный, воссозданный материал во время обучения. [6, стр. 114].

Повседневный опыт доказывает, что положительных результатов можно добиться, используя деловые игры в развитии профессиональных навыков и компетенций педагогов. Сами деловые игры делятся на несколько групп.

Это: имитационная, оперативная, ролевая, бизнес-театр, психо- и социодрама.

Деловые игры - это разновидность игры, которая развивает у учащихся навыки говорения в различных ситуациях, развивает модели диалога и монолога, развивает лидерские качества. В ходе деловых игр учащиеся учатся творчески работать и принимать правильные решения, смотреть на слова других сверстников, оценивать их мнение.

Давайте рассмотрим несколько вещей, которые отличают деловые игры от других методов обучения.

Наличие оппонента в деловой игре, а также необходимость принятия групповых решений, вносит дополнительный мотивационный фактор и эмоциональное напряжение. В большинстве случаев тематическая направленность и специфика компьютерных игр позволяют определить количество и среду участников. А многофакторная модель рынка, включенная в программу, определяет уровень конкуренции. Всем участникам деловой игры очень важна Справедливая, четкая, всем известная система оценок. Система оценок в компьютерной деловой игре формируется по правилу и задается алгоритмом, который постоянно выполняется вне настроения участников. Поэтому можно говорить об объективной машинной оценке. Однако, по возможности, игру лучше проводить под руководством опытного преподавателя, который сможет объяснить участникам игры результат и наладить работу компьютерной системы.

Игры на смекалку-вид игры, формирующий логическое мышление учащихся, в каждом задании даны варианты ответов, среди которых необходимо найти правильный ответ. Изобретательность-основная особенность игр: здесь должны быть даны готовые ответы к заданиям, и учащиеся должны выполнить задание в зависимости от уровня усвоенных знаний. Игры на смекалку можно использовать при объяснении пройденного урока, закреплении нового урока.

Поисковые игры-это форма игры, которая приучает учащихся к самостоятельному мышлению, систематизации и обобщению усвоенных знаний, поиску неизвестного в процессе усвоения новых знаний. В ходе поисковых игр учащиеся стремятся самостоятельно решать проблемы, учатся выполнять задания 
различными способами. К поисковым играм относятся: загадки, кроссворды, скороговорки, метаграммы. Поисковые игры целесообразно использовать при прохождении новых материалов.

Ролевые игры-форма игры, предназначенная для развития творческого мышления учащихся, совершенствования их умения делать новаторские мысли и выводы. Сюжетно-ролевые игры выполняют особую функцию в сочетании воображения, воображения учащихся. В ходе этой игры учащиеся учатся высказывать и аргументировать свое мнение, свободно вступать в языковое общение. Ролевые игры развивают словарный запас и язык учащихся, позволяют учащимся планировать игру, продолжать игру, оценивать мнение другого человека

Сомерсет Моэм очень серьезно относился к игровым элементам в художественном произведении. Несмотря на то, что писатель не разработал теорию реальной игры, в своих художественных произведениях, эссе, особенно в книге "Подводя итоги”, он много говорил об игре и искусстве, о его значении в жизни человека.

Игра-Древний культурно-исторический феномен. Понятие игры встречается в работах античных философов. Он имеет очень большое понятие и изучается в различных областях техники и искусства, науки. Игра считается объектом исследования психологов, философов, экономистов, историков культуры, этнографов, антропологов, теологов, искусствоведов и литераторов и др.

Сегодня сфера понятия “игра" с каждым днем расширяется, все шире распространяется в различных сферах жизни и культуры. Благодаря этому большой интерес к игре проявляют гуманитарные и не гуманитарные науки.

Выдающийся русский психолог П. П. Блонский указывал, что игра не рассматривается только в физиологическом, биологическом или индивидуально-психологическом отношении. "Просматривая существующе теории игр, становится богатым тот факт, что до сих пор не ясно, что такое игра-понятие, пишет он, - что такое игра? сам вопрос почему? без предварительного специального исследования показывает, что вопрос находится на ранней стадии исследования. Необходимо провести ряд комплексных специальных исследований, только по результатам которых можно получить окончательное решение игровой проблемы”

Игра имеет различное определение: игра-это свободная модель самосознания человека, игра-это экспериментальные признаки и функции социальных отношений между людьми. В названных исследованиях принимается следующее определение: игра-это форма образа жизни, которая является основой и фактором культуры.

Теоретические рассуждения об игре в европейской традиции мы встречаем в проекте Платона “идеальное государство".

Согласно мнению Платона, игра-дело, особенно достойное человека, хотя в ней она не проявляется как личность, а подчиняется.

Игра-суть красоты. На самом деле материальное состояние сливается с духовным состоянием, объектом субъектом; это сама жизнь и ее образ. Такова природа искусства. Даже перед самым реалистическим образом искусствовед не забывает, что перед ним условный мир. Для получения эстетического удовольствия требуется определенное несоответствие между изображенным и бейлендером. По э. Канту отсюда могут исходить два типа искусства. Один “дошел до иллюзии”, другой - “преднамеренно попахивает нашими чувствами”.

Затем Ф. Шиллер развеселил идею Э. Канта об игровой характеристике культуры и искусства. По его определению, “красота является объектом, побуждающим к игре”. Ф. Шиллер мог видеть в игре черты человеческого образца, если говорить по его словам “человек играет только тогда, когда он имеет полное значение этого слова, и только тогда, когда он играет, он становится человеком”.

Конкретная цель человеческой жизни это игра, и нет необходимости прилагать дальнейшие усилия потому что она берет на себя всю реальность, но в духовном ином образе.

Не снизится ли стоимость такого понятия высшего уровня, как “красота”, которое предъявляется всем исследователям игр, приравниваясь к игре и пустым вещам, обозначаемым в игровой среде, и не станет ли это ограничением понятия красоты просто игрой или ограничением понятия красоты красотой? Ф. Шиллер, отвечая на вопрос: “из всех обстоятельств человека, мы можем назвать его просто игрой, зная, что только игра показывает, что он является совершенным существом и раскрывает его двойственную природу?” , что ставит вопрос.

Ф. Шиллер утверждает: “человек должен играть только с красотой и играть с красотой”.

Понятие "игра", как и понятие "отражение", порожденное эстетической игрой, тесно связанное с ней, имеет особый характер и занимает особое место в жизни человека, как искусство между сознанием и жизнью. Игра является для Ф. Шиллера не только источником искусства, но и феноменом, отражающим специфику искусства. Поэтому Ф. Шиллер утверждал, что древние игры-это деятельность человека в свободное время по теории Г. Спенсера, продолжающей игру Ф. Шиллера, в процессе игры ребенок вытесняет из себя излишнюю силу. Стремясь раскрыть мотив игры, К. Бюлер предложил теорию удовлетворенности (удовлетворения от самого действия, независимо от результата) как основного мотива игры.

Повышение требований к качеству образования становится важнейшей проблемой и условием развития системы среднего образования. Тем самым предпринимаются усилия по обновлению его содержания на основе фундаментальных принципов его интеграции, практической направленности и преемственности. 
Целью современного образования в средней школе является дальнейшее развитие исторически сложившейся педагогической системы на основе создания условий для формирования социально активной, творческой личности, профессиональной компетентности. Таким образом, в программе развития образования РК до 2010 года «приоритет будет иметь не механическая передача знаний, умений, навыков, а формирование самосовершенствующейся личности, способной к самореализации, анализу, использованию информационных ресурсов, преобразованию идей и развитию в соответствии с условиями быстро меняющегося мира».

Основными структурными элементами игры являются: конечное намерение, сюжет или содержание игры, игровые действия, роли, правила игры, которые рождаются из самой игры и создаются детьми или предлагаются взрослыми. Эти элементы тесно связаны между собой и представляют игру как своеобразную деятельность детей.

Игра, как методика обучения и обмена опытом старшего поколения с младшим поколением, издавна используется людьми. В народной педагогике, дошкольных и внешкольных учреждениях широко используется игра. В современных школах, рассчитывающих на повышение интенсивности и активизацию учебного процесса, игровая деятельность используется в следующих случаях:

- Как самостоятельная технология освоения понятия, темы и даже раздела учебной дисциплины;

- Как один из элементов крупномасштабной технологии (иногда достаточно важный) ;

- Как урок (предмет) или его часть (введение, объяснение, закрепление, упражнение, наблюдение).

Модель урока в игровой форме возникает при участии учебных ситуаций и игровых методов в ходе урока, которые служат стимулом к обучению, пробуждают у учащихся желание учиться. В ходе учебного процесса была проведена экспериментальная работа по изучению игровой деятельности. Он состоял из трех ступеней.

- Констатирующий эксперимент;

- Формирующий эксперимент;

- Проверочный эксперимент.

Целью констатирующего эксперимента является анализ уровня развития творческих способностей учащегося по учебному предмету, а также определение уровня заинтересованности и активности учащегося. На данном этапе эксперимента были проведены тестовые работы или тест успешности для определения профессиональных и учебных достижений учащихся.

Анализ показал, что на уроках с использованием игровой технологии значительно повышается познавательная активность и творческие способности учащихся, повышается активность некоторых видов деятельности, благодаря чему наглядно проявляются различия в уровне грамотности учащихся.

Формирующий эксперимент направлен на повышение уровня познавательной активности ученика в процессе урока.

Средствами качественных показателей у учащихся повышается мотивация к знаниям, формируются организаторские способности, учатся работать в группе, развивается коммуникативная компетентность, креативность мышления, а также многие виды деятельности.

Таким образом, проведенная экспертиза заключалась в следующем::

- Желательно, чтобы игра включалась в занятия по каждому предмету, несмотря на разнообразие;

- Использование игры на уроке-состояние соотношения эффективности учебного процесса;

- Результативность игры зависит от ее правильной организации;

- Проведение игры в ходе урока, позволяет реализовать воспитательную цель обучения.

- Создание и внедрение игры в учебный процесс способствует быстрому и успешному решению основных учебных задач

Использование игры на уроке сводится к следующим основным условиям:

- игра ставится перед учащимися как задание;

- учебная деятельность учащихся подчиняется правилам игры;

- учебный материал используется в качестве игрового инструмента;

- в учебную деятельность игра входит как элемент работы;

- результат игры подводится сразу;

Для использования игрового элемента на уроке при такой подготовке необходимо учитывать следующие моменты:

- воспитательная цель;

- используемые визуальные эффекты;

- экономия времени;

- будет ли игра интересной?;

- контроль активности учащихся.

Очень важную роль в процессе урока играет то, чтобы учащимся было полностью понятно цель и требования, правила игры. С помощью игрового метода мы повышаем их интерес к предмету, тренируемся выражать свою мысль, мнение, точку зрения, слышать ответ другого человека, дополнять его, выражать свои достижения и недостатки. 
Подытоживая, мы заметили, что игра затягивает учебный процесс, повышает мотивацию ребенка к обучению. Игра представляет собой сумму определенных способностей, которые можно выразить так:

внимание + восприятие + память + мышление + суждение. Игра издавна использовалась казахским народом в целях воспитания детей. В общенародной педагогике в процессе применения игровых технологий был создан сборник произведений А. Байтурсынова, одного из первых казахских мыслителей, одного из первых педагогов «...обучая ребенка игре, вовлекая его в игру, дети должны учить, как они себя чувствуют».

Список использованных источников и литературы:

1. Педагогические технологии. под.ред В. С. Кукушина. Г. Ростов-на-Дону-издательский центр "МарТ". 2010. c. 12.

2. А. Кусаинов, А. А. Булатбаева. Методология образовательной деятельности. Г. Алматы-ТОО "Издательство \& A". 2010. с. 108.

3. А. П. Панфилова. Инновационные педагогические технологии: активное обучение 2-е изд. Г. Москва издательский центр «Академия". 2011. с. 112.

4. Хейзинга Иохан. Человек играющий. - 2003. с. 118.

5.казахские национальные игры журнал.Вестник педагогики. №4-2010. с. 123.

6. Калкенова А. Роль игры в обучении-казахстанская школа. 2007. №3. с. 114.

7. Кусаинов А. А., Булатбаева А. А. Методология образовательной деятельности,

Г. Алматы, 2011 год, ТОО «Издательство\&А» $[81,82,83,84,85$.

8. А. П. Панфилова, Инновационные педагогические технологии: активное обучение 2 -е издание, г. Москва, 2011 год, издательский центр "Академия" [3]

9. Короткова М. В. Методика проведения игр и дискуссий на уроках истории. - М.: Изд-во ВЛАДОСПРЕСС, 2001. - 256 с. [4] 